در اسة مقارنة في السلوك القيادي من حيث الاهنمام بالعمل و العلاقات بين مدربي كرة اليد وكرة القدم من وجهة نظر دار الناعبين

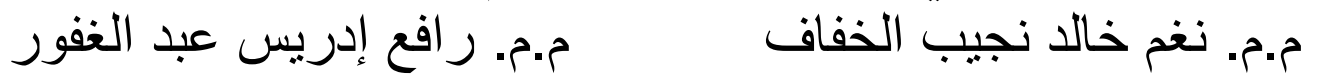
جامعة الموصل / كلية التربية الرياضية

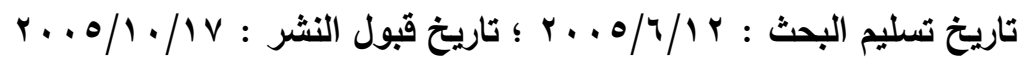

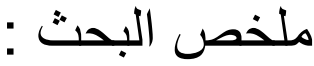 \\ هاف البحث إلى التعرف على:
}

ا. الفروق في السلوك القيادي من حيث الاهتمام بالعمل بين مدربي كرة اليد وكرة القدم من

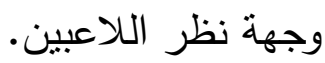

r. الفروق في السلوك القيادي من حيث الاهتمام بالعلاقات بين مدربي كرة اليد وكرة القدم من

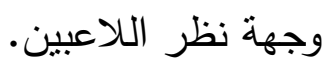

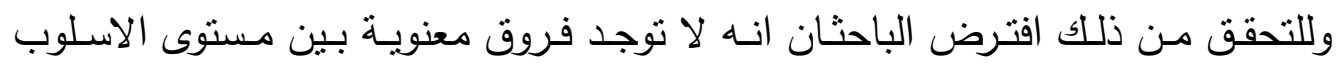
القيادي لمدربي لعبتي كرة اليد وكرة القدم من حيث الاهتمام بالعمل والعلاقات.تكونت عينة البحث من (Y) لاعباً لمنتخبي كلية التربية الرياضية بكرة اليد وكرة القدم، استخدم الباحثان

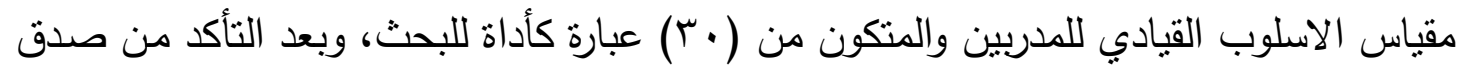

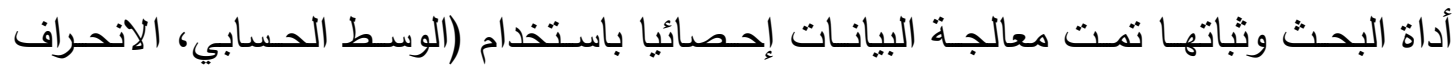

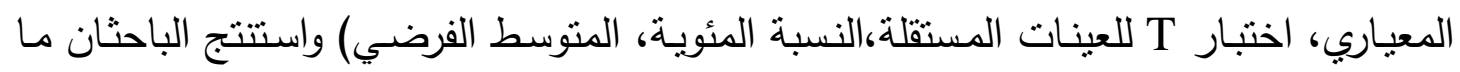
يأتي: ا ـ امـتلاك مدربي كرة اليــ وكرة القدم مستوى ايجـابي مـن السلوك القيـادي المهتم بـالأداء

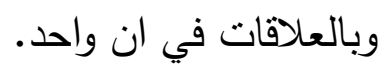

r. تثابه ظروف معظم اداء وتدريبات فعالتي كرة اليد وكرة القدم من حيث العمل الجماعي

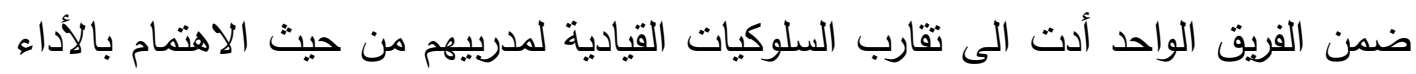
وبالعلاقات. 


\title{
Studying the Leadership Styles Regarding Attention to Work and Relationships between Hand Beal and Football Coaches from Players Point of View
}

\author{
Assist. Lecturer \\ Nagham Khaled Nageeb \\ Assist. Lecturer Rafi. A. \\ Abdulgdfor \\ University of Mosul - College of Sport Education
}

\section{Abstract:}

The research aims to realizing:

1. The differences in the leading behavior regarding affection to work between hand ball and football coaches from players point of view

2. The differences in the leading behavior regarding attention to relationships between hand ball and foot ball coaches from players' point of view in order.

To approve this, the two researchers supposed no significant differences between leading manner level for the coaches of both handball and football as regarding attention to work and relationships. Researches sample consisted of (21) players of football and handball of physical college coaches leading manner measure has been used by researchers the measure consisted of (30) expressions as research tool. and after being certain from the truth of research tool and its stability, The data has been processed statistically by using (arithmetical mean, standard deviation independent sample $\mathrm{T}$ test percentage and hypothetical mean).

The two researchers conclude the following:

1. Handball and football coaches have positive level for leading behavior concerning performance and relationships simultaneously.

2. Circumstance analogy for most performance and trainings for both of handball and football regarding group action in one team that lead to the leading manners approach for coaches concerning performance and relationships. 
إن موضوع القيادة من المواضيع ذات الاهتمام الكبير من قبل العلمـاء على اختلاف تخصصاتهم، لذا احتلت جوانب عديدة من حياة الفرد وتتاولها الباحثان بمناهج مختلفة وهنالك من التهن

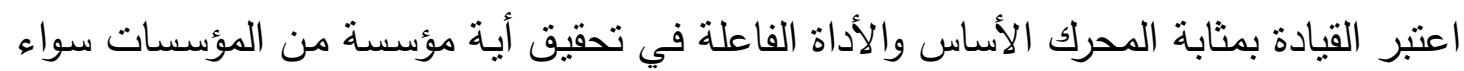

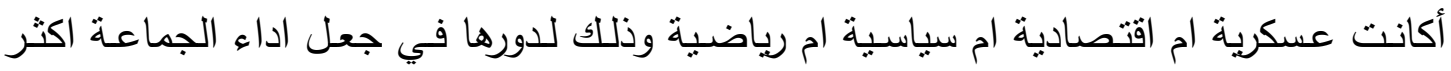

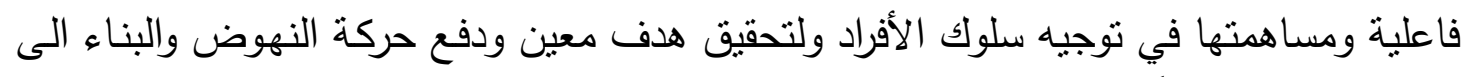

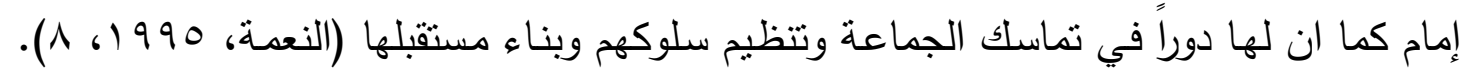

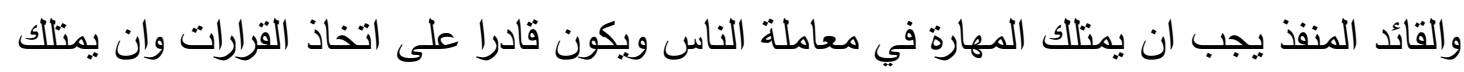

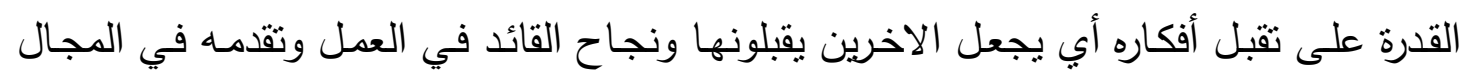

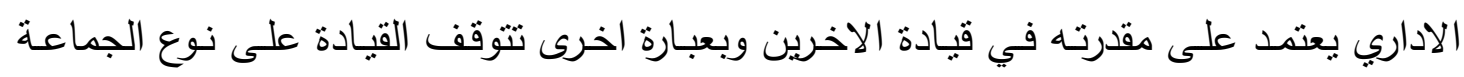

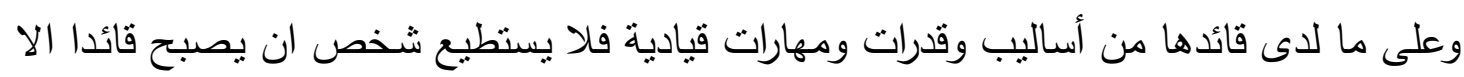

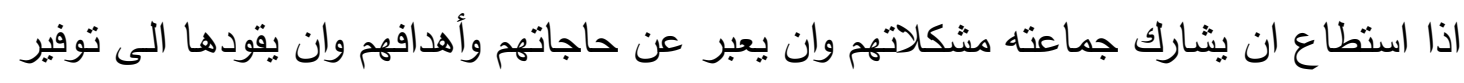
هذه الحاجات وبلوغ الأهداف.

إن الرياضة حركة أجنماعية نأتي في قمة التتظيمات الاجتماعية احتياجا لتوفير القيادات

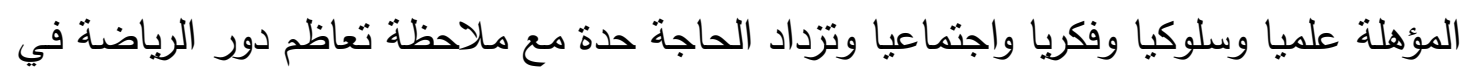

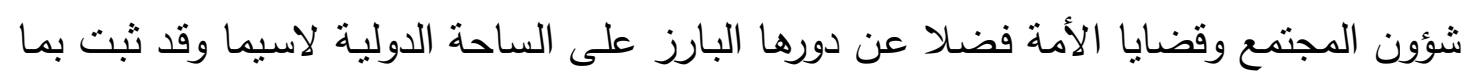

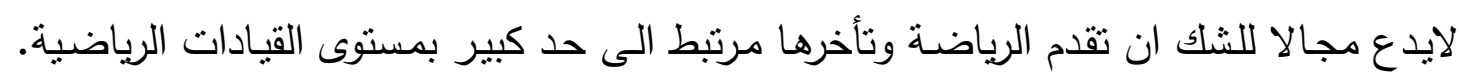

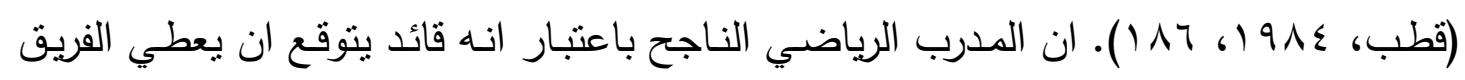

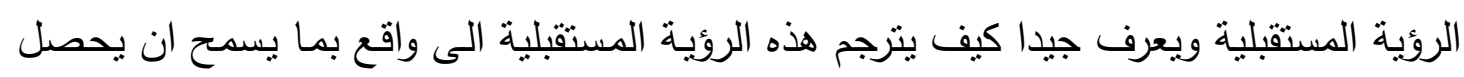

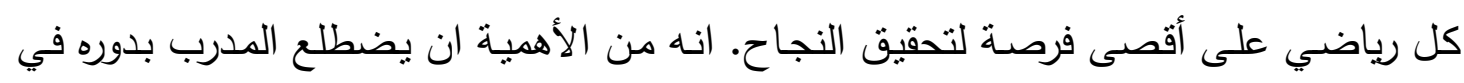

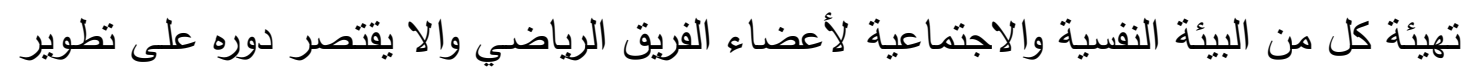

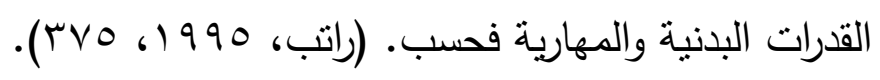

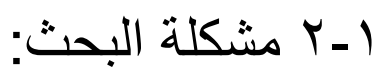

يعد الددرب الرياضي بمثابة قائد ومربي وموجه له دور فعال في العطلية التدريبية وفي التئي

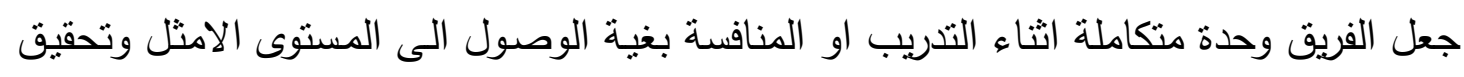

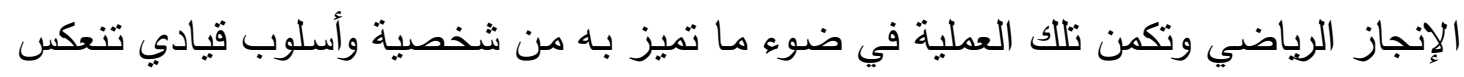

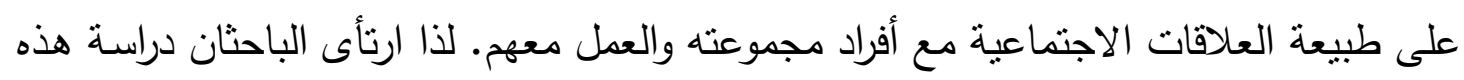
الشكلة دراسة ميدانية من خلال التعرف على الاسلوب القيادي للمدربين من وجهة نظر لاعبد لاعبيه. 


$$
\text { يهذف البحث الى التعرف على: البحف }
$$

ا ـ الفروق في السلوك القيادي من حيث الاهتمام بالعمل بين مدربي كرة اليد وكرة القدم من وجهة نظر اللاعبين. r. الفروق في السلوك القيادي من حيث الاهتمام بالعلاقات بين مدربي كرة اليد وكرة القدم من وجهة نظر اللاعبين.

$$
\text { ا - ع فرض البحث }
$$

لا توجد فروق ذات دلالة معنوية بين مستوى الاسلوب القيادي لمدربي الألعاب الجماعية

من حيث الاهتمام بالعمل والعلاقات.

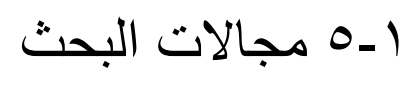

- المجال البشري: لاعبي منتخبا كلية التربية الرياضية بكرة اليد وكرة القدم. - المجال المكاني: كلية التربية الرياضية - جامعة الموصل.

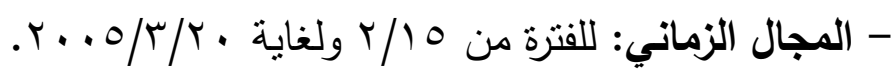

Y - الدر اسات النظرية و الدر اسات المشابهة:

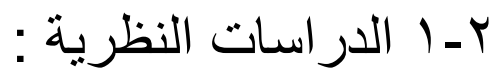
: الق القياد

القيادة هي عملية تربوية اجتماعية لازمـة لكل جماعة تريد ان تحقق تفاعلا اجتماعيا

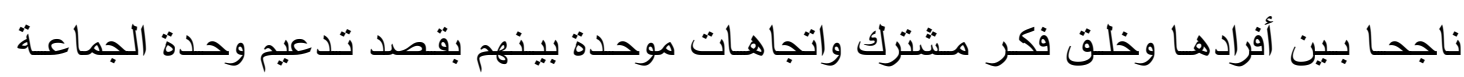

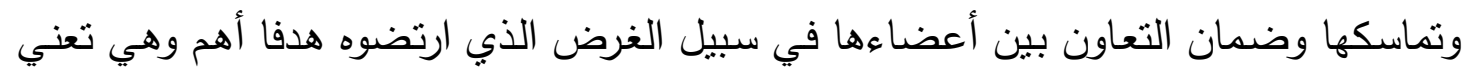

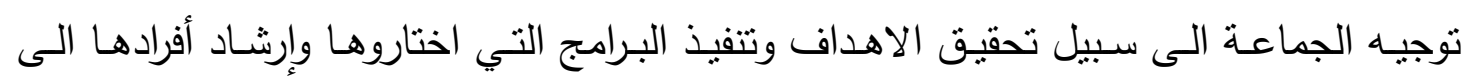

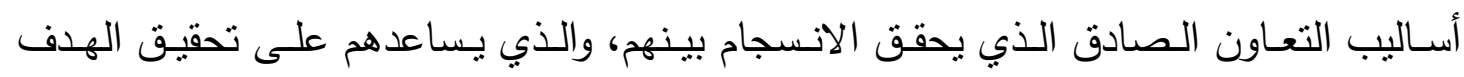

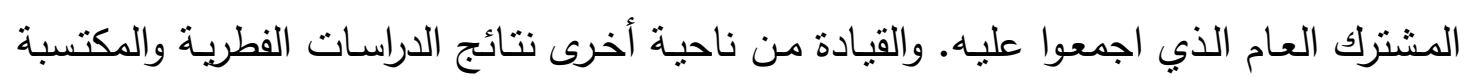

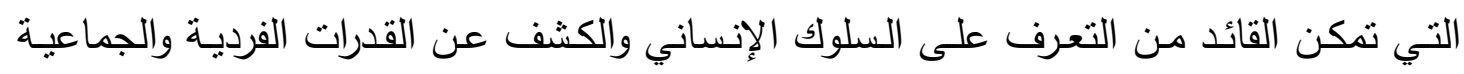

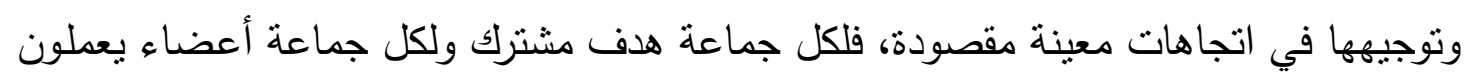

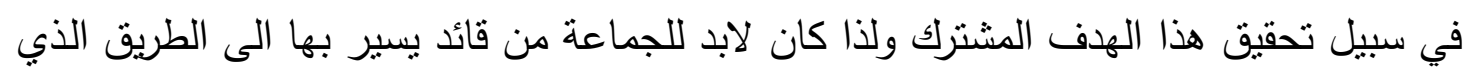

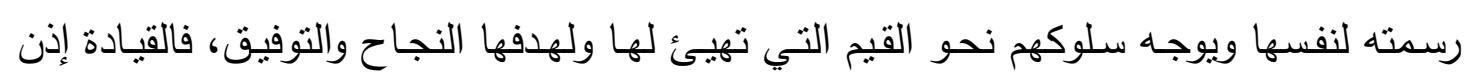
ضرورة اجتماعية عرفها الإنسان منذ عرف حاجته للتعامل مع غيره من الناس ومنذ إدراك أهية

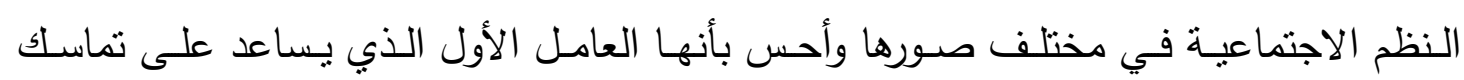


الجماعـة وأنها العنصر الأسـاس في تحقيق رغباتها القياديـة بالدفهوم اللغوي هي الأخذ بزمـام

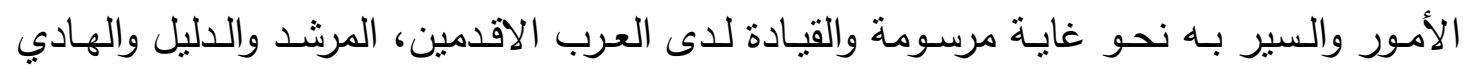

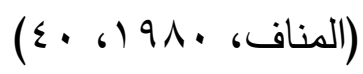

لذا توجد القيادة حيثما وجدت الجماعة او ظهرت الحاجة الى الفعل الجماعي وتتطور

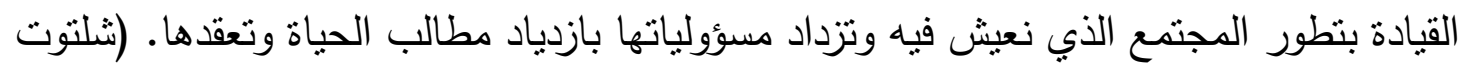

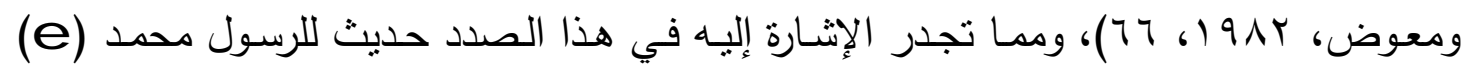
حيث قـال: (اذا خرج ثلاثـة في سفر فليؤمروا احدهم) صدق رسـول اله (حديث مسند رواه

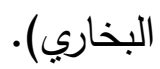

وركزت بعض التعاريف على الفرد في القيادة إلا إن التعريفات الحديثة للقيادة لا ترتبط

بالفرد فقط ولكن بالموقف وبالهدف وبالجماعة ولذلك فان مواصفات القائد الناجح ليست كافية

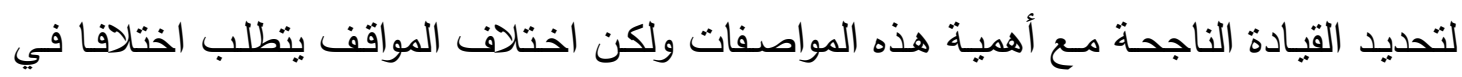
أساليب القيادة كما إن الهدف الذي تسعى إليه الجماعة يؤثز في عملية القيادة تعني نمطا معينا

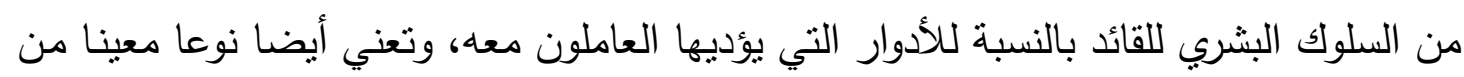

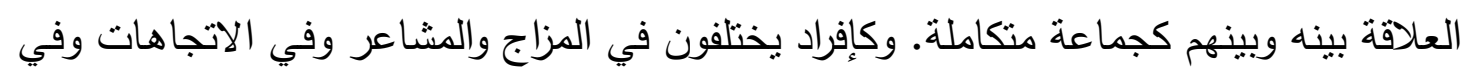

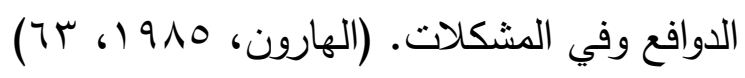

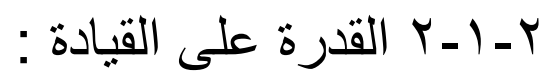

يلاحظ ان أقدم تعريفات القيادة تتاولها الباحثان من جانب الثخصية الواجب نوافرها

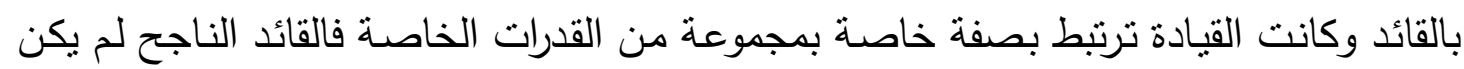

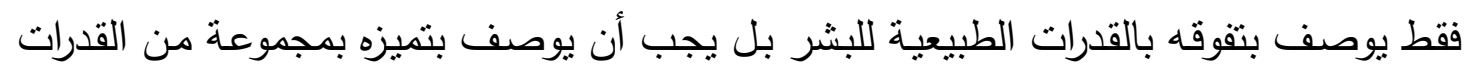

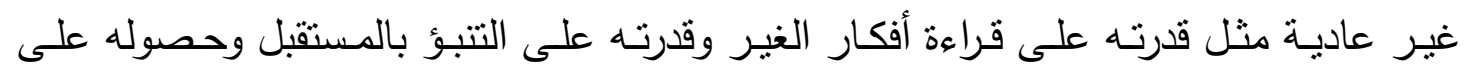

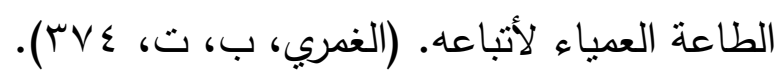

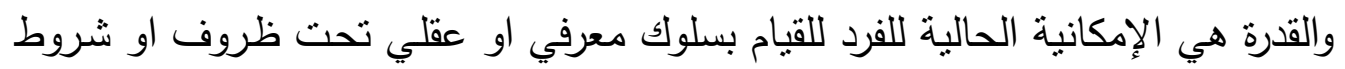

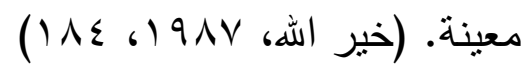

Y - ا ـ العلاقة بين اللاعب و المدرب ومسؤولياته :

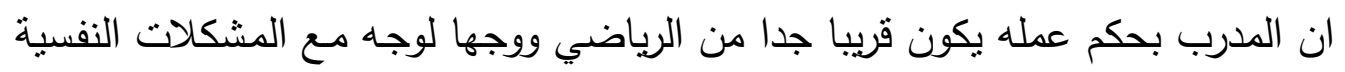

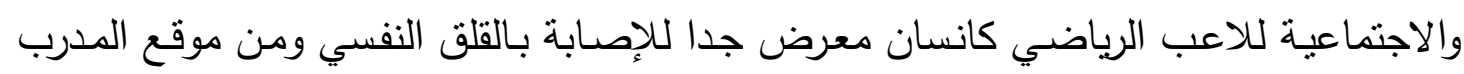
الى نفسية اللاعب يستطيع إزالة او منع هذا القلق بمعرفة العوامل النفسية المؤثرة وطريقة إزالتها

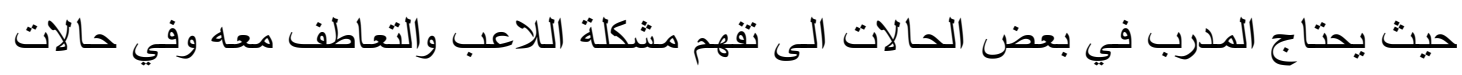


أخرى يبدي شيئًا من الحزم والتأنيب للاعب حيث ان الكلمة المناسبة تستطيع حل كثير من المواقف الحرجة التي اذا تركت تؤدي الى عواقب ونئ وخيمة. ان نفسية المدرب تلعب دورا كبيرا في اثثاء عملية التدريب التي تنعكس على المتدربين

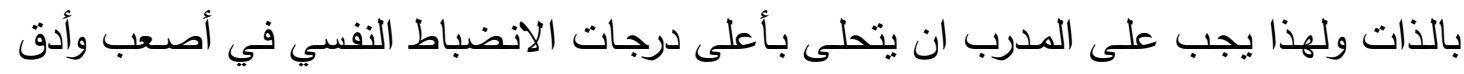

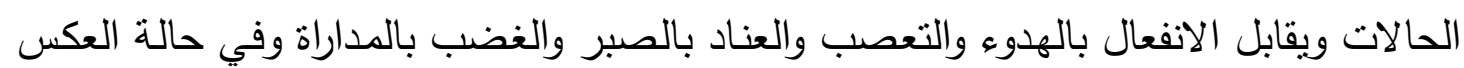

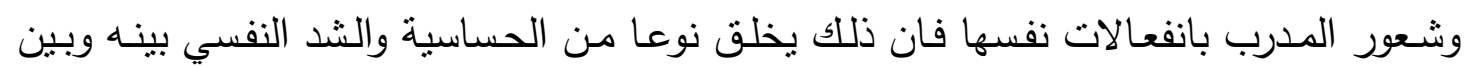

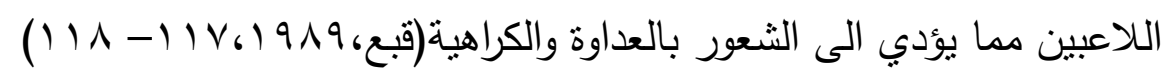

$$
\begin{aligned}
& \text { Y - ـ ـ أهم و اجبات المدرب الرياضي : الهي } \\
& \text { 1. اختيار الموهوبين والمتميزين من الرياضيين. }
\end{aligned}
$$
r. تخطيط العملية التدريبية وتوفير مستلزماتها. r. الإشراف على تتفيذ العملية التدريبية. ع. تشخيص الخلل في البرنامج التدريبي. 0. رعاية اللاعبين قبل وبعد وإثناء المنافسة. T. توجيه ورعاية وإرشاد اللاعبين.

Y ـ ـ ـ ـ ويمكن تقسيم المدرب الرياضي الى الأقسام التالية: 1. من حيث الفعالية التي يتولى تدريبها:

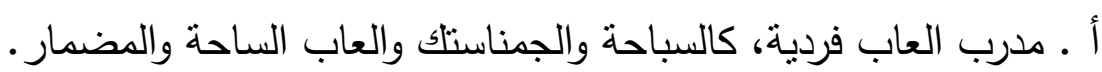
ب. مدرب العاب فرقية، كالقدم واليد والطائرة والسلة. ج. مدرب العاب قتالية، كالملاكمة والمصارعة. r. من حيث المؤهلات العلمية والعملية:

$$
\text { ب. }
$$

ج. مدرب موجه. (الطالب، 999 1، محاضرات دراسات عليا) 
ويؤكد (عوض، 911 (1) بان هناك أسلوبين شائعين للقيادة هما الاسلوب الاوتوقراطي والأسلوب الديمقراطي (The Democratic style) فالأسلوب (The (The Decratic Style) الأوتوقراطي يوصف قائدها كونه يركز على إن تكون السلطة بيده وينفرد بوضع الخطط وإصدار

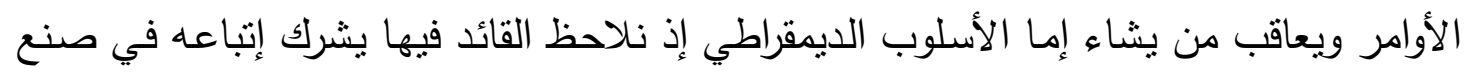

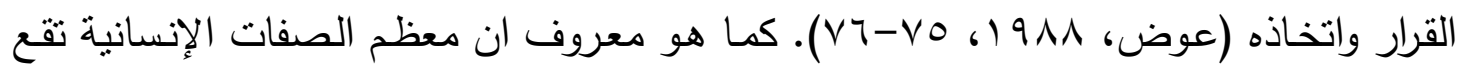

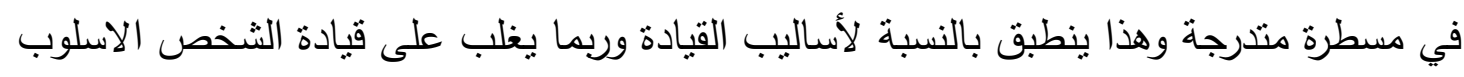
الاوتوقراطي ولكن ليس من الضروري ان يغلب على أسلوبه كتركيز نحو التتظيم والعمل ومقابل

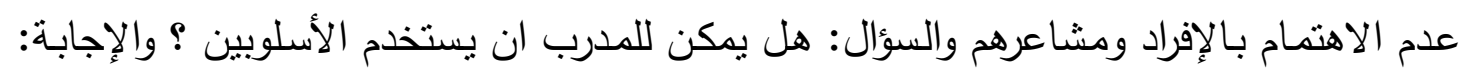

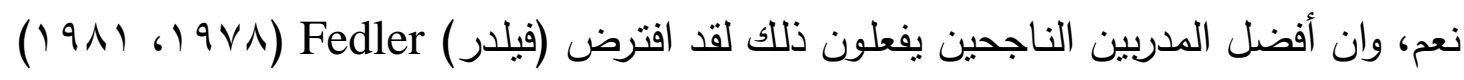
خلال دراسته لا يحقق فعالية منساوية في جميع المواقف واخذ (فيلدر ) وزملائه النموذج التوافقي

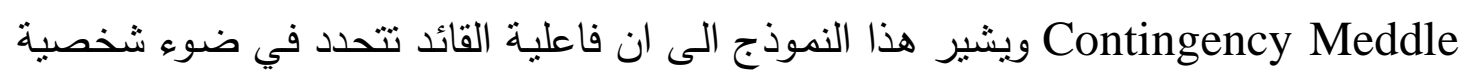
القائد وسيطرة القائد على الموقف وان الاسلوب الثخصي او الدافعي إما ان يتميز بالاتجاه الذي في فئي

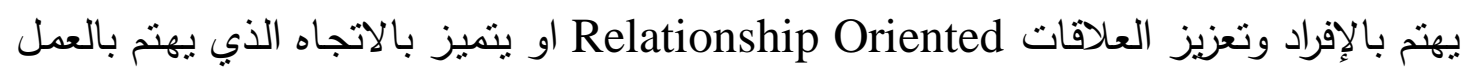
Task Oriented

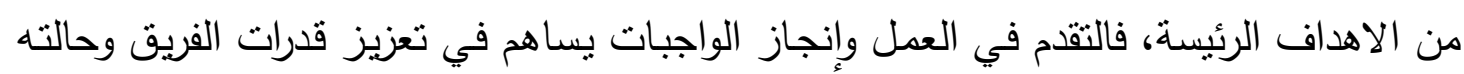

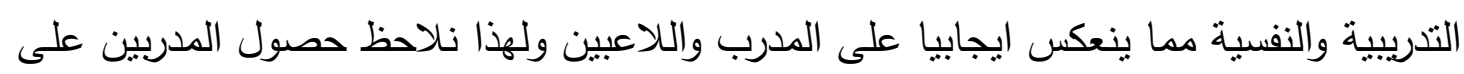
سلوك قيادي ايجابي يهنم بالعلاقات لدعم العلاقات التعاونية والايجابية مع أفراد مجموعته.

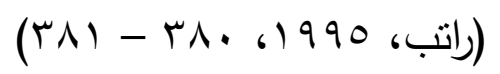

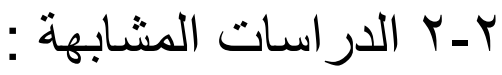

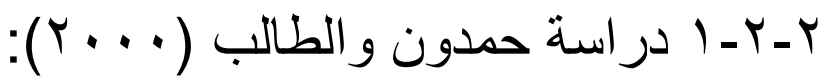

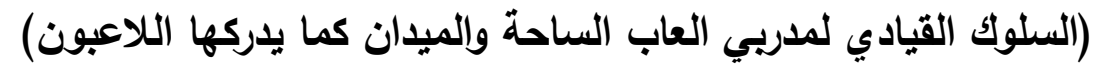

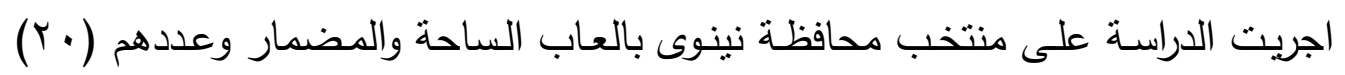
لاعباً وهدفت الدراسة الى الاجابة عن السؤالين:

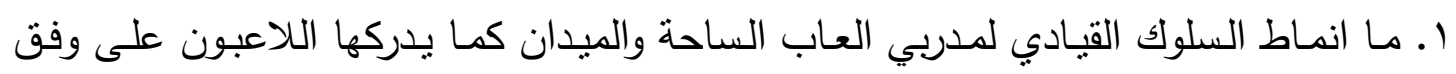

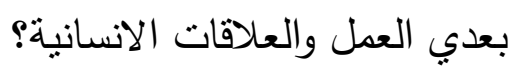
r. هل هناك فروق ذات دلالة احصائية في مستوى بعدي العمل والعلاقات الانسانية برأي العاني

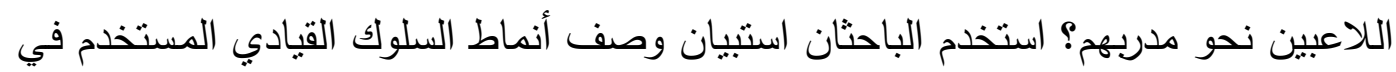
دراسة فروقة (ب99 (1) وهذا الاستبيان أعده الى العربية محمد اسماعيل يوسف مطورا إياه

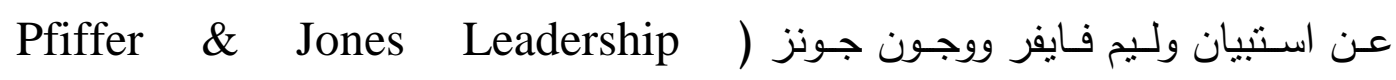
وإيجاد صدقها وثباتها، عالج الباحثان البيانات إحصائيا باستخدام معامل \&uestionnaire 
الارتباط البسيط والنسبة المئوية واختبار (ت) والوسط الحسابي المرجح وخلصت الدراسة إلى إلى

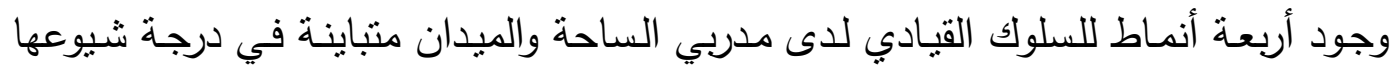

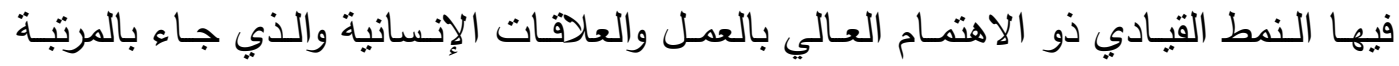

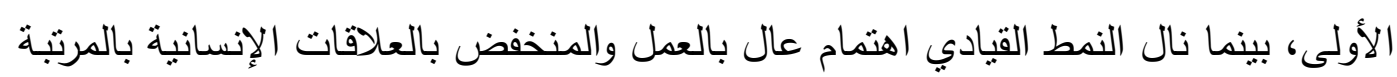

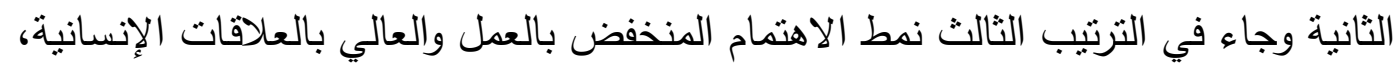

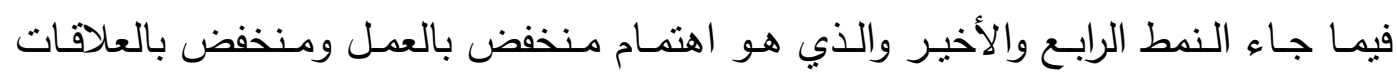

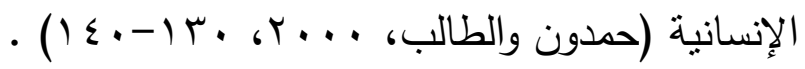

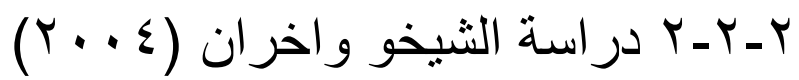

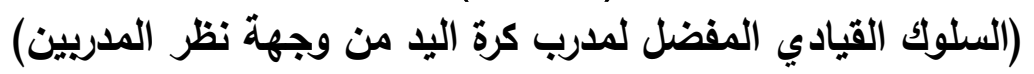

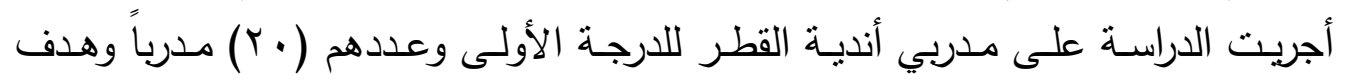

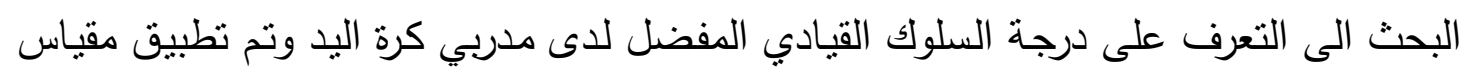

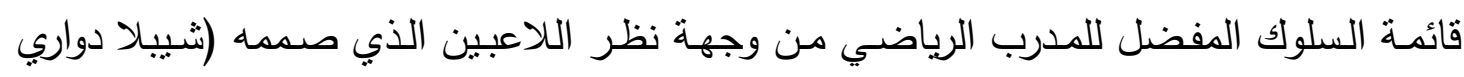

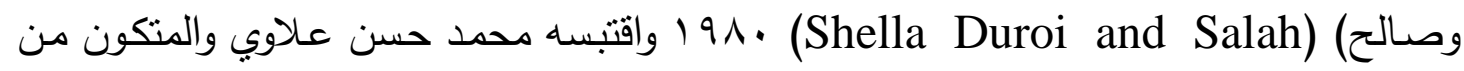

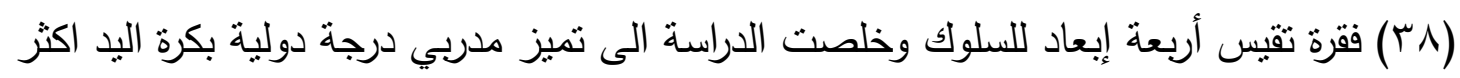

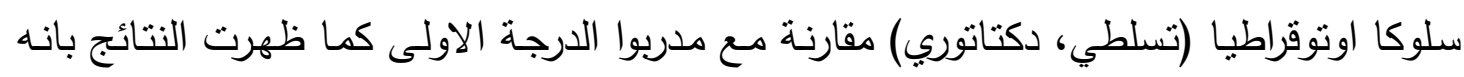

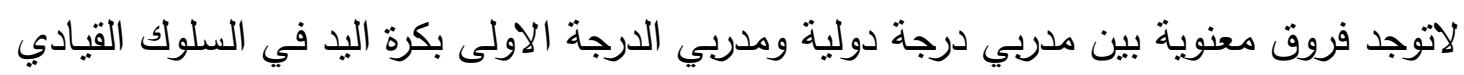

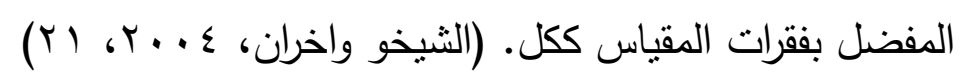

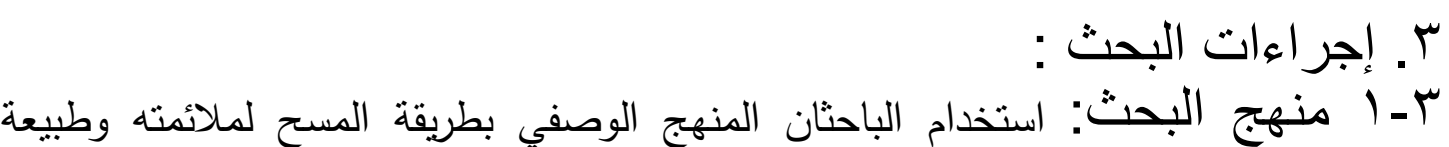
البحث. ب- Y عينة البحث : تمثلت عينة البحث بلاعبي منتخبا كلية التربية الرياضية بكرة اليد وكرة

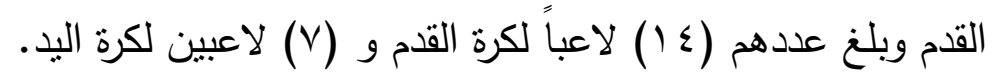

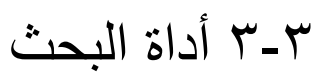

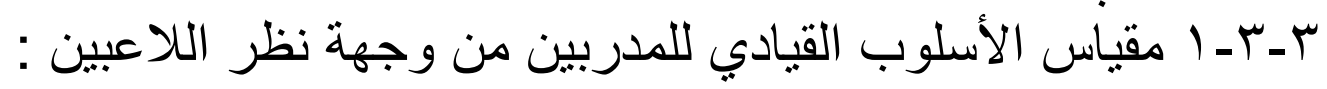

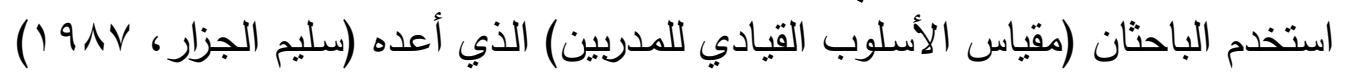

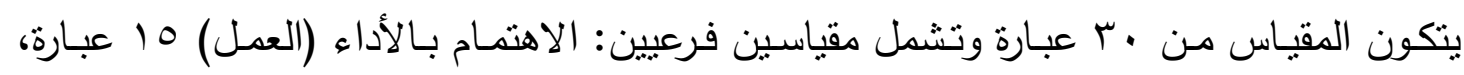

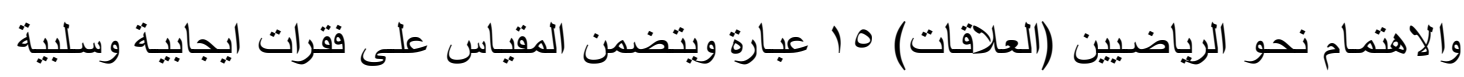

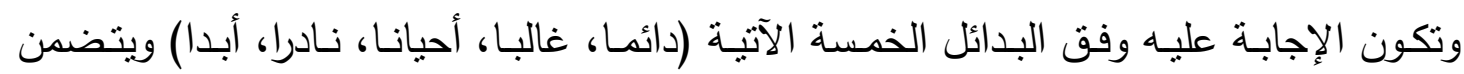

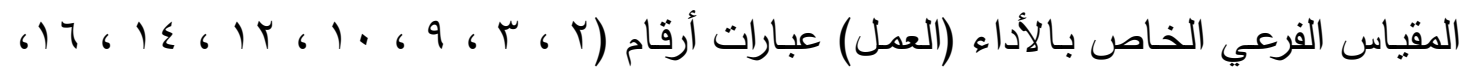

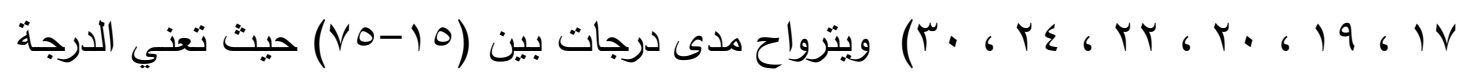

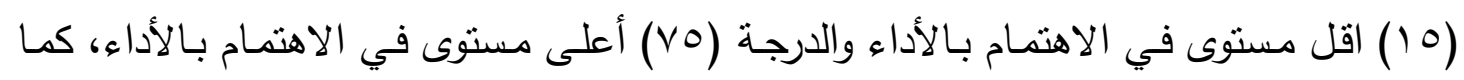




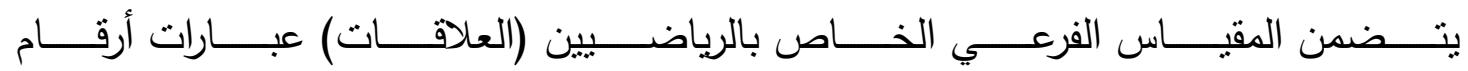

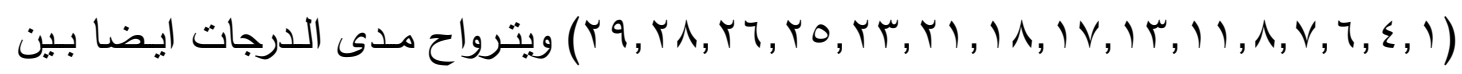
V0 حيث تعن Vo, 10

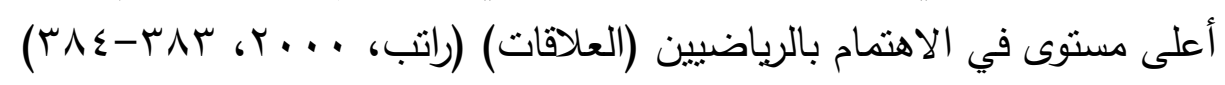

r- - المو الصفات العلمية للمقياس:

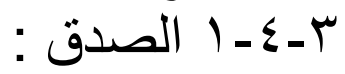

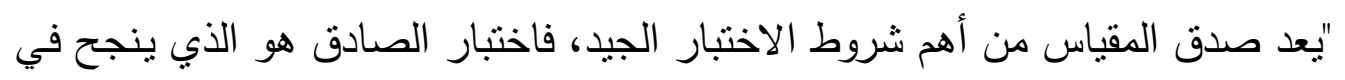

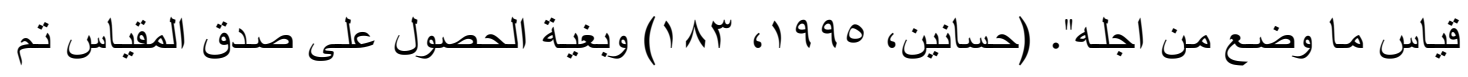

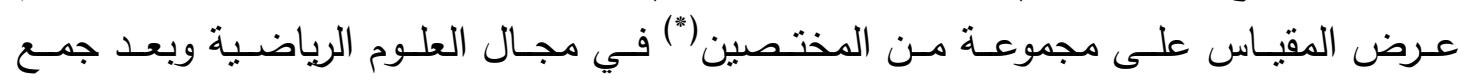

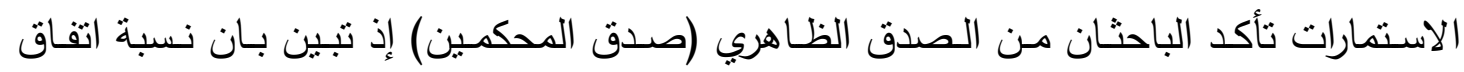

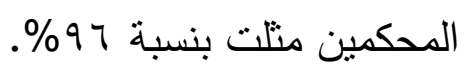

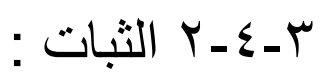

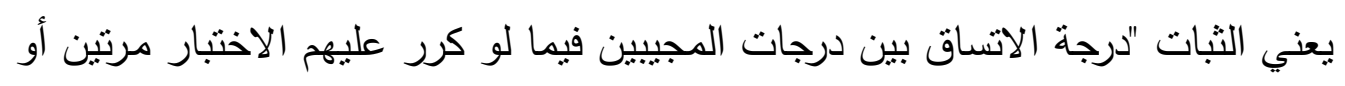

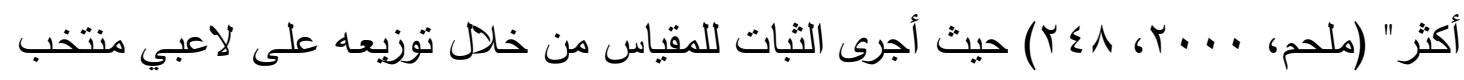

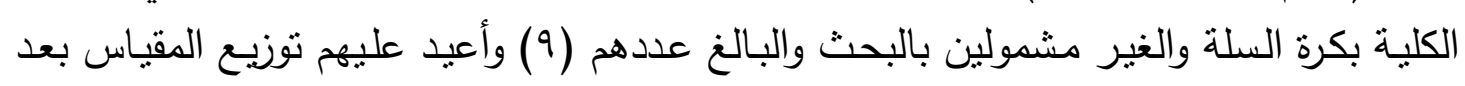

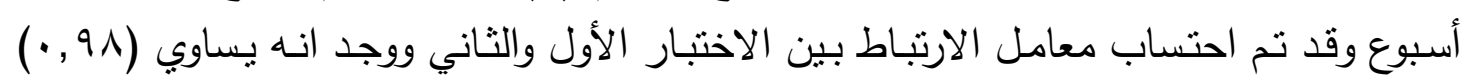
وذللك يدل على إن المقياس يتمتع بمعامل ثبات عالي.

$$
\begin{aligned}
& \text { بـ- المعالجات الإحصائية } \\
& \text { - الوسط الحسابي. } \\
& \text { - الانحراف المعياري. } \\
& \text { - اختبار T للعينات المستقلة. } \\
& \text { - النسبة المئوية. } \\
& \text { - المتوسط الفرضي. - النئ. - }
\end{aligned}
$$

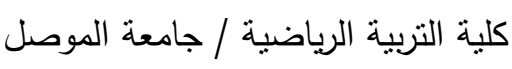

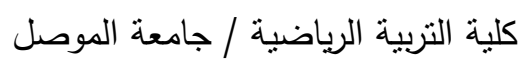
كلية التربية الرياضية / جامعة الموصل
(") - أ. أ.د راشد حمدون

- أ.م.د ناظم شاكر الوتار

- م.د زهير يحي 
ع. ع عرض النتائج ومناقشتها

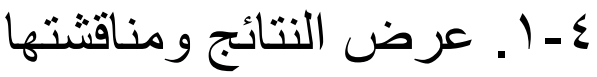

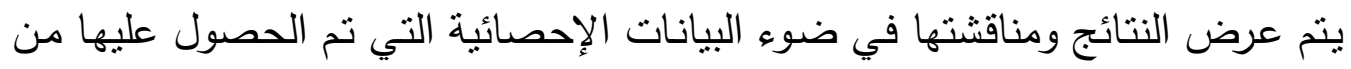

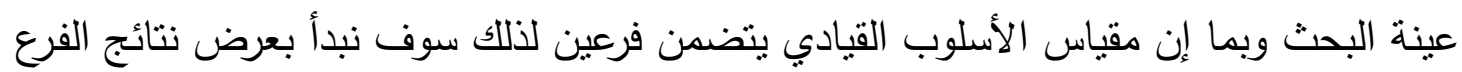
الأول فيما يخص الاسلوب القيادي المهتم بالعمل ومن ثم الأسلوب القيادي المهتم بالعلاقات.

$$
\text { (الجدول (1) }
$$

يبين الأوساط الحسابية والانحرافات المعيارية وقيمة T المحتسبة بين لاعبي كرة اليد وكرة القدم في الأسلوب القيادي المهتم بالعمل والاند

\begin{tabular}{|c|c|c|c|c|}
\hline قالمحسوية ت & $\varepsilon^{ \pm}$ & س & ن & الفريق \\
\hline \multirow{2}{*}{$1,1 \leqslant$} & $\Lambda, I V$ & $0 \leqslant, 9 \pi$ & v & كرة اليد \\
\hline & $9, \cdot 1$ & $O V, \cdot T$ & $1 \varepsilon$ & كرة القدم \\
\hline
\end{tabular}

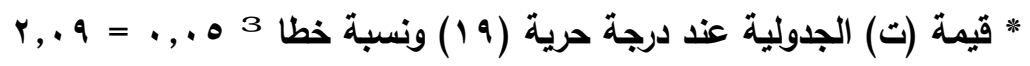

من الجدول (1) يتضح ما يأتي : بلغ الوسط الحسابي للأسلوب القيادي المهتم بالعمل

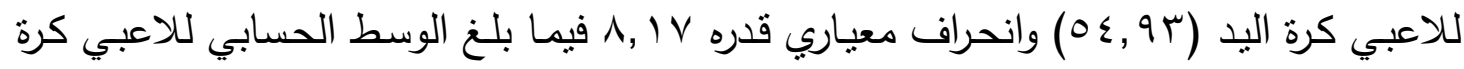

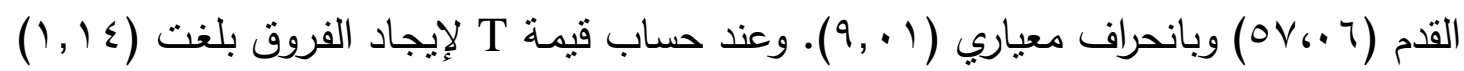

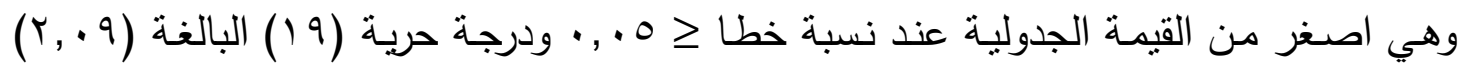
أي إن الفرق غير معنوي.

(r) (الجدول

يبين الأوساط الحسابية والانحرافات المعيارية وقيمة T المحتسبة بين لاعبي كرة اليد وكرة القدم في الاسلوب القيادي المهتم بالعلاقات

\begin{tabular}{|c|c|c|c|c|}
\hline قالمحسوية ت & $\varepsilon^{ \pm}$ & س & ن & الفريق \\
\hline \multirow{2}{*}{1,10} & $1 \cdot, \wedge 1$ & $07, Y q$ & v & كرة اليد \\
\hline & $V, I T$ & ON, rV & $1 \varepsilon$ & كرة القدم \\
\hline
\end{tabular}

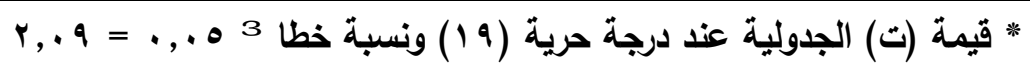




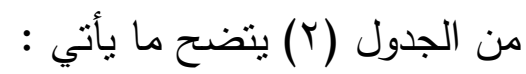

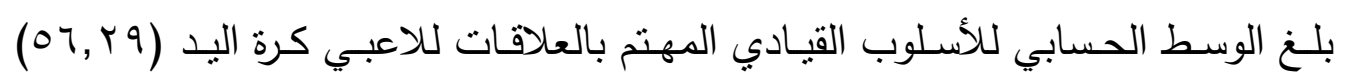

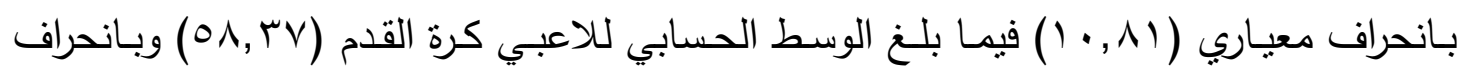

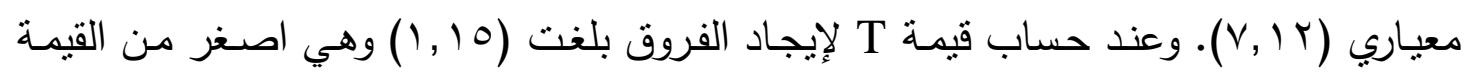

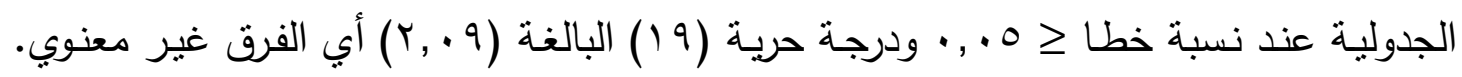
ومن خلال ما تقدم نلاحظ بأننا قد حصلنا على نتائج لا تثنير إلى معنوية الفروق بين مدربي كرة اليد وكرة القدم سواء بالعمل أو العلاقات ويعزو الباحثان سبب عدم ظهور فروق معنوية بين الاسلوب القيادي المهتم بالعمل وبالعلاقات لدى المدربين الى إن تشابه طبيعة ظروف العمل الجماعي ضمن الفريق الواحد، فالمدرب في الفعاليات الجماعية يسعى دائما الى تحقيق التآلف والانسجام بين أعضاء الفريق والذي يؤدي الى وحدة الهدف للوصول بالفريق الى أعلى مستوى من الإنجاز، فضلا عن اهتمام المدربين يجب ان ينصب في توطيد العلاقات بين اللاعبين وتقويتها وهذا لا يتحقق الا عندما يكون المدرب ديمقراطيا في تعامله مـ اللاعبين ولكن ضمن حدود معينة لذا نجده يحاول زرع التقة في نفوس لاعبيه ويسمح لهم بمناقشته في بعض امور التدريب كمشاركة اللاعب او اللاعبين في وضـع الخطط والى غير ذلك حيث يذكر (راتب،

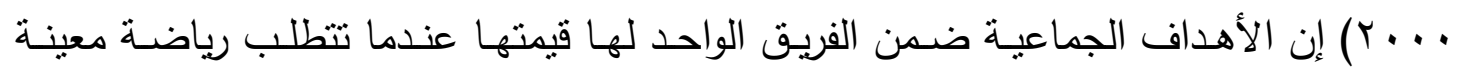
مستوى مرتفعا من التعاون والتوافق كما هو الحال في الالعاب الجماعية مثل كرة اليد او كرة القدم او كرة السلة عندئذ تمثل قيمة في تتظيم وزيادة الدافعية نحو انجاز العمل (راتب، .... ب، 


\section{ه. الاستنتاجات و التوصيات:

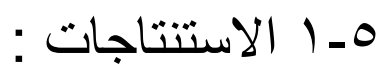

خلال عرض النتائج ومناقشتها تم استتناج ما يأتي :

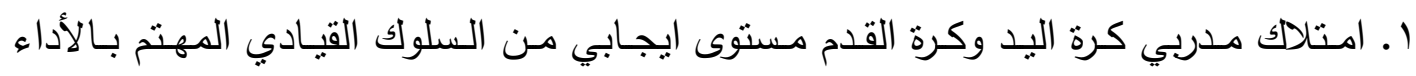

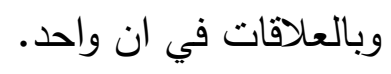

r. تشابه ظروف معظم اداء وتدريبات فعالتي كرة اليد وكرة القدم من حيث العمل الجماعي

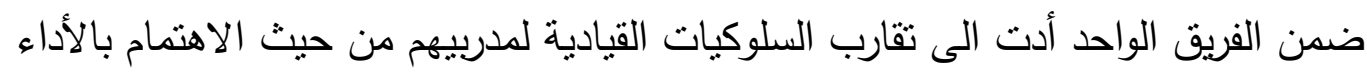
وبالعلاقات.

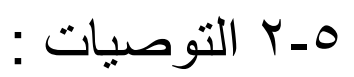

في ضوء النتائج التي أسفرت عنها الدراسة الحالية يوصي الباحثان بما يأني :

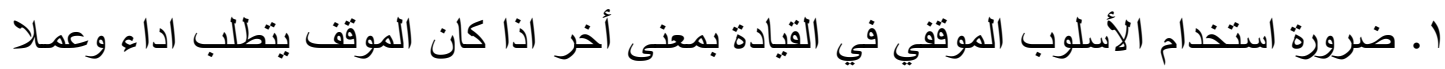

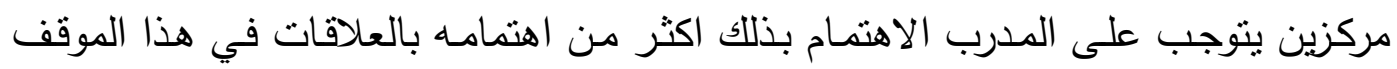

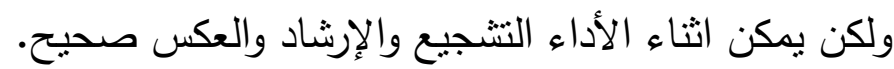
r. ضرورة إيمان المدرب بان جو الفريق يجب ان يكون صحيا بمعنى ان بناء جو عمل ايجاء ولئي

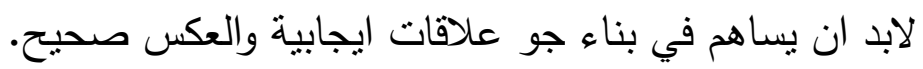

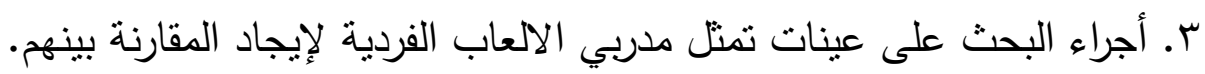




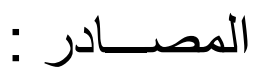

(. حسانين، محمد حسين: (990 ()) بناء وتقنين الاختبارات والمقاييس في التربية البدنية، طب،

دار الفكر العربي، القاهرة.

r. حمدون، راشـد والطالب، ضياء مجيد: ( . . ب)، السلوك القيادي لمدربي العـاب الساحة

والميدان كمـا بـدركها اللاعبون، مجلـة الرافدين للعلـوم الرباضية، العدد العشرون، المجلد

السادس.

r. راتب، إسـامة كامل: (990 (1) علم نفس الرباضـة، المفاهيم التطبيقية، دار الفكر العربي،

مصر

ع. راتب، إسـامة كامل: ( . . ب) علم النفس الرياضية المفاهيم - التطبيقات، طّ. دار الفكر

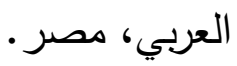

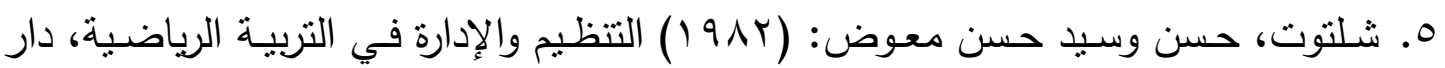
المعارف، القاهرة.

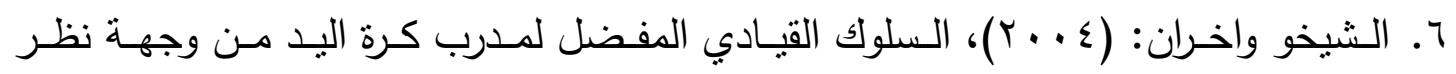

المدربين، مجلة الرافدين للعلوم الرياضية، العدد السادس والثلاثون، المجلد العاشر •

V. الطالب، ضياء مجيد: (999 (99) محاضرات طلبة الدراسات العليا في مادة علم التدريب، كلية

التربية الرياضية، جامعة الموصل.

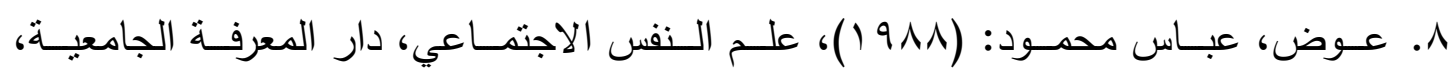
الإسكندرية.

9 . قبع، عمار عبد الرحمن: (919 (19) الطب الرياضي، مدير مطبعة جامعة الموصل. • ا. قطب، سعد محمد وآخرون: (ع^و () الإدارة والتتظيم في مجال التربية الرياضية، مطابع جامعة الموصل.

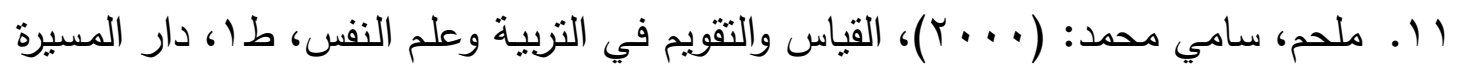
للنشر والتوزيع والطباعة، عمان، الاردن.

ז ا. . المناف، جميل كامل: ( • 9 (1) القيادة والأزمة الحضارية، دار الرشيد للنشر، بغداد. س ا. النعمـة، وليد خالـد: (990 (1) القدرة القياديـة لدى رؤسـاء الاتحاديـات الرياضـية العراقيـة (رسالة ماجستير غير منشورة) جامعة الموصل.

ع ا. الهارون، مساعد: (910 (1) الإدارة في المجال الرياضي، مؤسسة الكويت للتقدم العلمي. 
ملحق (1)

مقياس الأسلوب القيادي للمدربين

\begin{tabular}{|c|c|c|c|c|c|c|}
\hline 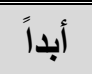 & 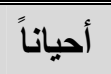 & نادراً & غالباً & دائماً & 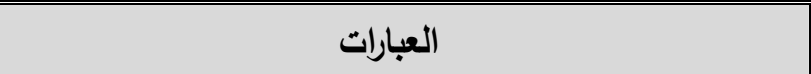 & $ت$ \\
\hline & & & & & يحمي التلاعبين ويدافع عنهم & 1 \\
\hline & & & & & يعتبر الخلاف في الرأي تحديدا لسلطانه & r \\
\hline & & & & & يتيح الفرصة للابنكار والابداع & r \\
\hline & & & & & يسمح بالهشاركة في اتخاذ القرارات التي تهم الفريق & $\varepsilon$ \\
\hline & & & & & يقصر في واجباته التنريبية & $\circ$ \\
\hline & & & & & يهتم بالحوافز المادية والمعنوية & 1 \\
\hline & & & & & بيق في اللاعبين & v \\
\hline & & & & & يقدر مشاعر اللاعبين ويحس بإحساسهم & $\wedge$ \\
\hline & & & & & يجبر اللاعبين على تتفيذ أوامره & 9 \\
\hline & & & & & يشارك في الأداء اثثاء التدريب & 1. \\
\hline & & & & & محبوب وصديق لجميع اللاعبين & 11 \\
\hline & & & & & يوزع المسؤوليات بحيث يضع كل لاعب في المكان المناسب & ir \\
\hline & & & & & يعمل على قضاء اكبر فترة ممكنة مع اللاعبين & ir \\
\hline & & & & & يعمد الى انتحال الأعذار عند تقصيره وإهماله & $1 \varepsilon$ \\
\hline & & & & & يستفيد من إمكانيات وقدرات جميع اللاعبين & 10 \\
\hline & & & & & برفض التجديد والتغيير & 17 \\
\hline & & & & & ينمي احترام الذات لاى اللاعبين & iv \\
\hline & & & & & يناقت أراء اللاعبين ومقترحاتهم & 11 \\
\hline & & & & & لديه خبرة فنية كبيرة & 19 \\
\hline & & & & & يكون واتقا في أدائد & $r$. \\
\hline & & & & & يهتم بجميع أعضاء الفريق & r) \\
\hline & & & & & يحقق نتائج متواضعة للفريق & rt \\
\hline & & & & & بساعد اللاعبين على حل مشاكلهم داخل النادي وخارجه & r \\
\hline & & & & & لا يهتم بنتائج الفريق & $r \varepsilon$ \\
\hline & & & & & يشى على جهود اللاعبين & ro \\
\hline & & & & & يتمتع بروح طيبة وحسنة & rч \\
\hline & & & & & يجعل اداء الفريق يتميز بالجدية & rV \\
\hline & & & & & بسعى الى توفير جو أفضل للاعبين & rs \\
\hline & & & & & يبث جو السعادة والمرح بين اللاعبين & rq \\
\hline & & & & & يستخدم الطرق والأساليب الحديثة في التدريب & $r$. \\
\hline
\end{tabular}




$$
\text { صدق المقياس (r) }
$$

\section{بسم الله الرحمن الرحيم}

$$
\text { نهويكم أطيب تحياتنا.. }
$$

في النيـة أجراء البحث الموسوم (دراسـة الأسـلوب القيـادي لعدد مـن مدربي الألعـاب (الجماعية من وجهة نظر اللاعبين).

ونظرا لما تثمتعون به من خبرة ودراية في مجال العلوم الرياضية نرفق لكم طيا المقياس المستخدم لهذا الغرض، راجين تفضلكم بـالإطلاع عليـه وبيـان صـاحية المقبـاس مـن الناحيـة العلمية، علما إن المقياس يتكون من خمسة بدائل (دائما، غالبا، نادرا، أحيانا، أبدا).

$$
\text { اللم الخبير: }
$$

التاريخ والتوقيع:

الباحثان 